\title{
Agathomerus (Agathomeroides) flavomaculatus (Coleoptera, Megalopodidae, Megalopodinae): morfologia da larva e do adulto
}

\author{
Elisa B. Carvalho ${ }^{1} \&$ Marcela L. Monné ${ }^{1,2}$ \\ 1. Museu de Zoologia, Universidade de São Paulo, Caixa Postal 42494, 04218-970 São Paulo, SP, Brasil. \\ 2. Bolsista da FAPESP.
}

\begin{abstract}
Agathomerus (Agathomeroides) flavomaculatus (Coleoptera, Megalopodidae, Megalopodinae): larva and adult morphology. The larva of Agathomerus (Agathomeroides) flavomaculatus (Klug, 1824), collected in Capsicum baccatum L. (Solanaceae), is described and illustrated. The adult redescription includes characters of mouthparts, wing venation, endosternites and male and female terminalia. For the first time a larva of subfamily Megalopodinae is described.
\end{abstract}

KEYWORDS. Agathomerus, Capsicum baccatum, Megalopodidae, morphology.

RESUMO. A larva de Agathomerus (Agathomeroides) flavomaculatus (Klug, 1824), coletada em Capsicum baccatum L. (Solanaceae), é descrita e ilustrada. A redescrição do adulto inclui caracteres das peças bucais, venação da asa, endosternitos e terminálias masculina $\mathrm{e}$ feminina. Pela primeira vez uma larva da subfamília Megalopodinae é descrita.

PALAVRAS-CHAVE. Agathomerus, Capsicum baccatum, Megalopodidae, morfologia.

O gênero Agathomerus Lacordaire, 1845 apresenta 45 espécies na Região Neotropical e destas, 32 ocorrem no Brasil (BLACKWELDER, 1946; GUÉRIN, 1945, 1946, 1948, 1951). MonRós (1947), na revisão dos megalopodídeos argentinos, propôs cinco subgêneros em Agathomerus, alocando neles somente as sete espécies que ocorrem na Argentina. Em Agathomerus (Agathomeroides) incluiu apenas A. (Agathomeroides) flavomaculatus (Klug, 1824).

Pouco se sabe sobre os imaturos de Megalopodidae e a única larva conhecida é a de Palophagus bunyae Kuschel, 1990, descrita na subfamília Palophaginae (Kuschel \& MAY, 1990). No presente trabalho, a larva de Agathomerus (Agathomeroides) flavomaculatus é descrita pela primeira vez para Megalopodinae e o adulto é redescrito, incluindo caracteres das peças bucais, endosternitos, venação alar e terminálias masculina e feminina.

$\mathrm{O}$ material estudado pertence às seguintes instituições: DZUP, Coleção de Entomologia Pe. Jesus Santiago Moure, Departamento de Zoologia, Universidade Federal do Paraná, Curitiba; MNRJ, Museu Nacional, Universidade Federal do Rio de Janeiro, Rio de Janeiro; MZSP, Museu de Zoologia, Universidade de São Paulo, São Paulo.

\section{Agathomerus (Agathomeroides) flavomaculatus (Klug, 1824) \\ (Figs. 1-33)}

Megalopus flavomaculatus KLUG, 1824:57.

Agathomerus flavomaculatus; LACORDAIRE, 1845:683; ClavareaU in JUNK, 1913:12; BRUCH, 1914:348; LiMA, 1936:328; 1955:157; Blackwelder, 1946:635; Picanço et al., 1999:132.

Agathomerus (Agathomeroides) flavomaculatus; Monrós, 1947:186.

Larva (Figs. 1-9). Corpo (Fig. 1) subcilíndrico, curvo e com coloração esbranquiçada. Cabeça prognata, esclerotinizada, subarredondada e não retraída no protórax; endocarena alcança a margem anterior; sutura coronal longa; sutura frontal com aspecto de lira. Três estemas dispostos em fileira de cada lado. Clípeo transverso, subtrapezoidal, duas cerdas de cada lado. Labro transverso, margem anterior escavada e oito cerdas subapicais. Antenas (Fig. 4) curtas, três segmentos: $1^{\circ}$ quadrangular, $2^{\circ}$ cilíndrico e ligeiramente mais longo que o primeiro, $3^{\circ}$ (Figs. 4,5$)$ reduzido, com papilas sensoriais distais membranosas e, ao lado do $3^{\circ}$, um processo cônico diminuto. Mandíbulas (Fig. 2) simétricas, robustas, ápices bidenteados, com uma cerda curta mediana; penicilo ausente. Maxilas parcialmente membranosas; estipe largo, com uma cerda longa; cardo estreito, pouco distinguível, membranoso, sem cerdas; mala alongada, estreita, com cerdas curtas, simples, apicais; palpífero membranoso, com duas cerdas curtas; palpos maxilares 3 -segmentados, $2^{\circ}$ com duas cerdas curtas apicais, $3^{\circ}$ (Fig. 6) com papilas sensoriais distais. Lábio (Fig. 3): pré-mento transverso, com duas cerdas medianas; pós-mento alongado, com duas cerdas; lígula desenvolvida, com seis cerdas, duas basais longas e quatro apicais curtas, próximas entre si; palpos labiais esclerotizados, bisegmentados, glabros.

Protórax ligeiramente mais longo que o mesotórax ou metatórax. Pronoto moderadamente aplanado, com um par de cerdas longas e delgadas. Um par de espiráculos (Fig. 7) anulares, esclerotizados, laterais, na região intersegmentar entre pro- e mesotórax. Mesonoto e metanoto ligeiramente convexos, com cerdas longas, esparsas. Pernas (Fig. 8) curtas e grossas; coxa larga, transversa, com cerdas esparsas e moderadamente curtas; trocanter transverso; fêmur estreito e subcilíndrico, margem apical munida de cerdas curtas; tíbia curta e transversa, com uma cerda curta; tarsúngulo largo na base, ápice curvo.

Abdome 10-segmentado, cada um dos segmentos 

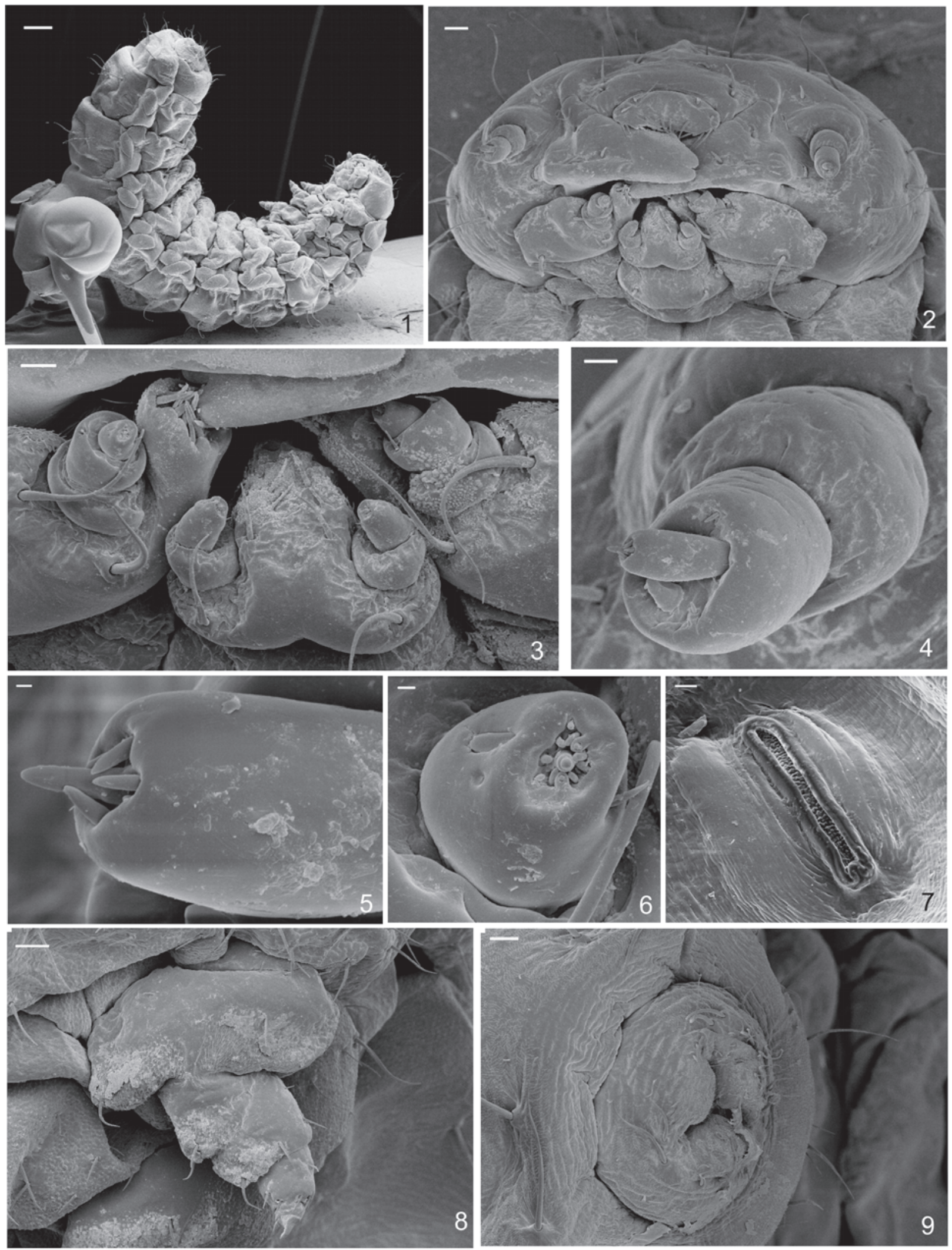

Figs. 1-9. Agathomerus (Agathomeroides) flavomaculatus (Klug, 1824), larva. 1, vista lateral (18x); 2, cabeça, frontal (100x); 3, detalhe das maxilas e lábio $(300 x) ; 4$, antena $(600 x) ; 5$, ápice do terceiro segmento antenal $(4000 x) ; 6$, detalhe do último segmento do palpo maxilar (2000x); 7, espiráculo torácico (500x); 8, perna protorácica (230x); 9, segmento abdominal X (130x). Barras, $300 \mu \mathrm{m}, 120 \mu \mathrm{m}, 30 \mu \mathrm{m}, 10 \mu \mathrm{m}, 4 \mu \mathrm{m}, 6 \mu \mathrm{m}, 30 \mu \mathrm{m}, 60 \mu \mathrm{m}, 60 \mu \mathrm{m}$, respectivamente. 
visível em vista lateral, com cerdas longas e esparsas. Tergos I-VIII bilobados dorsalmente, munidos de duas cerdas nos lados. Segmentos I-VIII com um par de espiráculos anulares, laterais; segmento $\mathrm{X}$ reduzido e arredondado; abertura anal em "Y" (Fig. 9).

Adulto (Figs. 10-33). Cabeça, antenas e região ventral, pretas; pronoto amarelo com mancha em forma de "M" preta; escutelo amarelo com margens pretas; élitros castanho-alaranjados com manchas ovaladas, antero-medianamente e no terço apical, amareladas. Corpo com pilosidade amarela.

Cabeça quase tão larga quanto longa; vértex deprimido, com pontos finos e adensados nos lados. Inserção das antenas pouco manifestas. Clípeo e labro com pêlos longos, esbranquiçados. Submento densamente pontuado. Olhos globosos, profundamente emarginados; lobo ocular superior truncado no ápice e inferior ovalado. Mandíbulas (Figs. 10, 11) cerca de duas vezes mais longas que largas; bordo interno com franja de pêlos alaranjados na metade anterior e, na região mediana, com inconspícua projeção aguçada; ápices aguçados. Maxila (Fig. 12): gálea dilatada para o ápice, alcança a base do terceiro artículo do palpo, com pêlos longos, mais adensados próximo à lacínia; lacínia com franja compacta de pêlos. Palpos maxilares com pêlos longos e esparsos; artículo basal curto, cilíndrico, cerca de 1/3 do comprimento do artículo seguinte; o segundo tão longo quanto o apical; o terceiro cônico e cerca da metade do apical, que é estreitado e afilado para a extremidade. Lábio (Fig. 13) com mento transverso e pêlos muito longos que alcançam o segundo artículo dos palpos labiais; lígula (Fig. 14) membranosa, com lobos bem desenvolvidos providos de pêlos dorsais curtos e esparsos; palpos labiais com pêlos longos e curtos, artículo apical estreitado na base e no ápice, $1 / 3$ mais curto que o anterior. Antenas com pêlos esparsos, alcançam o terço basal dos élitros. Escapo cilíndrico, obcônico, com comprimento subigual ao antenômero III; III-IV cilíndricos; V-X subserreados; XI estreitado no ápice; IV-XI subiguais em comprimento e aproximadamente 1/4 mais curtos que o III.

Protórax mais largo que longo, na base tão largo quanto os élitros; margem lateral arredondada. Margem anterior do pronoto com um sulco transversal profundo e outro raso próximo à margem posterior. Pronoto glabro, exceto alguns pêlos longos próximos aos ângulos anteriores; pontuação fina, rasa e esparsa. Prosterno com pontuação fina, densa, coberto com pêlos finos, curtos e esparsos; processo prosternal (Fig. 15) laminiforme na região mediana e ligeiramente alargado apicalmente; cavidade coxal anterior fechada. Proendosternito (Fig. 16) membranoso, mais longo que largo, com projeções desenvolvidas, arredondadas no ápice e convergentes. Mesoscuto (Fig. 22) com placa estridulatória. Escutelo triangular, com ápice arredondado. Mesosterno (Figs. 17, 18) curto, cavidade mesocoxal aberta lateralmente; pilosidade curta, densa e pontuação finíssima, esparsa. Processo mesosternal estreito, afilado no ápice e, em vista lateral, projetado. Mesendosternito (Fig. 19) obliquamente dirigido para o mesepímero e fusionado no ápice à parede interna do mesmo. Metepisterno ligeiramente estreitado para a região posterior, liso e glabro, exceto no terço anterior densamente pontuado, com pêlos longos e densos. Metasterno (Figs. 17, 18) convexo, distintamente mais projetado que o mesosterno, com pilosidade longa e densa. Sutura metasternal quase atinge a margem anterior. Metendosternito (Figs. 20, 21) hilecetóide, lâminas curtas e largas em relação aos braços e separadas por chanfro estreito ligeiramente anguloso; pedúnculo com cerca do dobro do comprimento das lâminas; braços perpendiculares às lâminas e divergentes entre si; implantes dos tendões desenvolvidos.

Élitros cerca de três vezes mais longos que o protórax, glabros, com pontuação fina e moderadamente densa. Úmeros arredondados e obliquamente truncados. Asas (Fig. 25) com comprimento cerca de duas vezes sua maior largura; lobo anal plicado, com dois lobos; Costa (C) alcança a metade apical, Subcosta $(\mathrm{Sc})$ restrita ao terço basal; célula da Radial (R) fechada, sub-retangular; s-m vestigial; ramo apical da Média-Anterior (MA) presente e pouco aparente; Plical (P) desenvolvida, encurvada na base, fundida à Cubital $(\mathrm{Cu})$; Empulsal $(\mathrm{E})$, na base, ligada à primeira Anal (1a); ramo da Empusal (Ea) pouco desenvolvido, apresentando um ramo curto no terço anterior; 2a fundida com a E+1a; Jugal (J) longa e desenvolvida, não atinge a borda; área carenada ausente. Pernas com pilosidade longa e moderadamente densa, anteriores e médias subiguais em comprimento, posteriores 1/3 mais longas que as demais. Procoxas e mesocoxas salientes e cônicas. Profêmures e mesofêmures lineares. Metafêmures distintamente dilatados. Tíbias ligeiramente mais longas que os fêmures, cilíndricas e com sulco dorso-longitudinal; esporões tibiais apicais delgados, curtos, subiguais em comprimento. Protíbias retas, meso- e metatíbias encurvadas. Metatarsômeros I-III subiguais em comprimento, $\mathrm{V}$ quase tão longo quanto os anteriores reunidos; escovas tarsais compactas. Garras simples. Empódio (Fig. 23) com região distal ligeiramente mais curta que a basal, com quatro cerdas longas.

Ventritos I-IV estreitos e subiguais em largura, com pontuação fina, esparsa e pilosidade longa, densa. Esternito $V$ cerca de quatro vezes mais largo que o anterior, com pontuação grossa, densa e margem apical truncada.

Terminália masculina. Tergito VIII (Fig. 24) subretangular, margem apical estreitada, região distal mediana truncada e com franja de pêlos curtos, eretos. Esternito VIII (Fig. 26) transverso, com borda apical sinuosa; apófise curta, cerca de 1/3 do comprimento do esternito. Arco ventral (Fig. 27) em forquilha, comprimento da apófise subigual ao dos braços. Tégmen (Figs. 28, 29) recurvo em vista lateral, com comprimento subigual à metade do comprimento do lobo médio; região distal com parâmeros fusionados e ápice sinuoso, com pêlos curtos e eretos; peça anelar ovalada e projeção apical desenvolvida, com cerca da metade do comprimento da região anelar. Lobo médio (Figs. 30, 31), em vista lateral, com a extremidade curvada; lobo ventral mais longo que o dorsal, acuminado apicalmente; lobo dorsal com extremidade sinuosa; apófises basais arqueadas, cerca do dobro do comprimento da porção apical; saco interno membranoso, com ducto ejaculatório flageliforme, longo, pelo menos duas vezes o comprimento do lobo médio. 

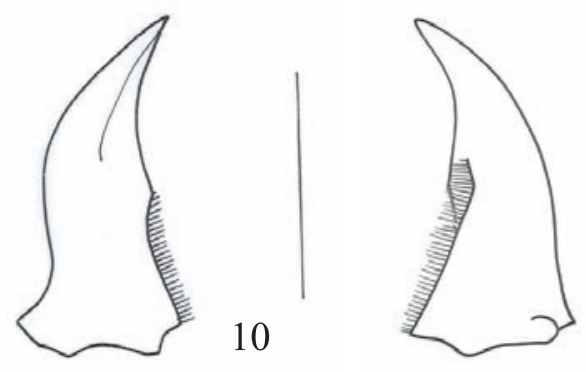

11
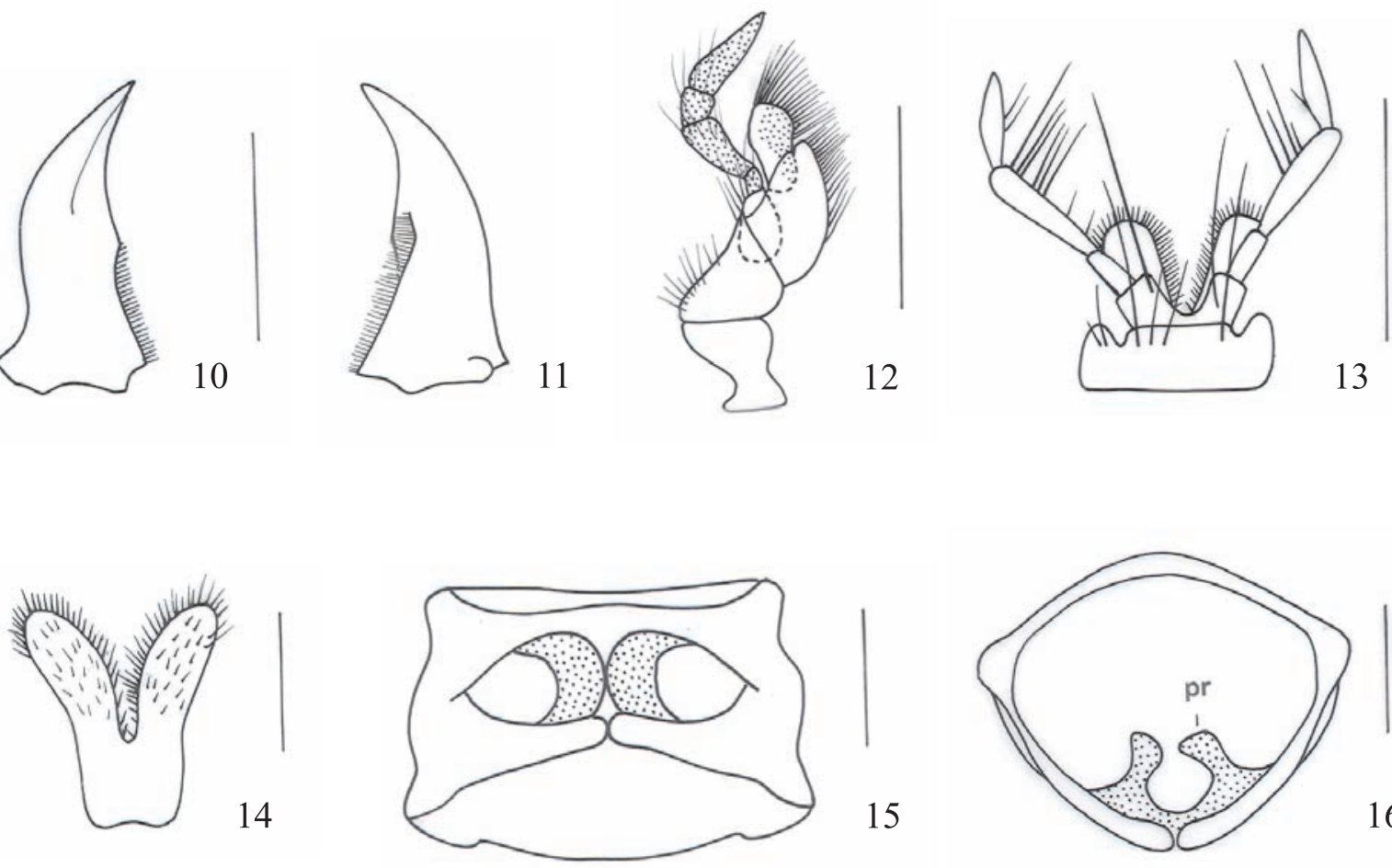

15
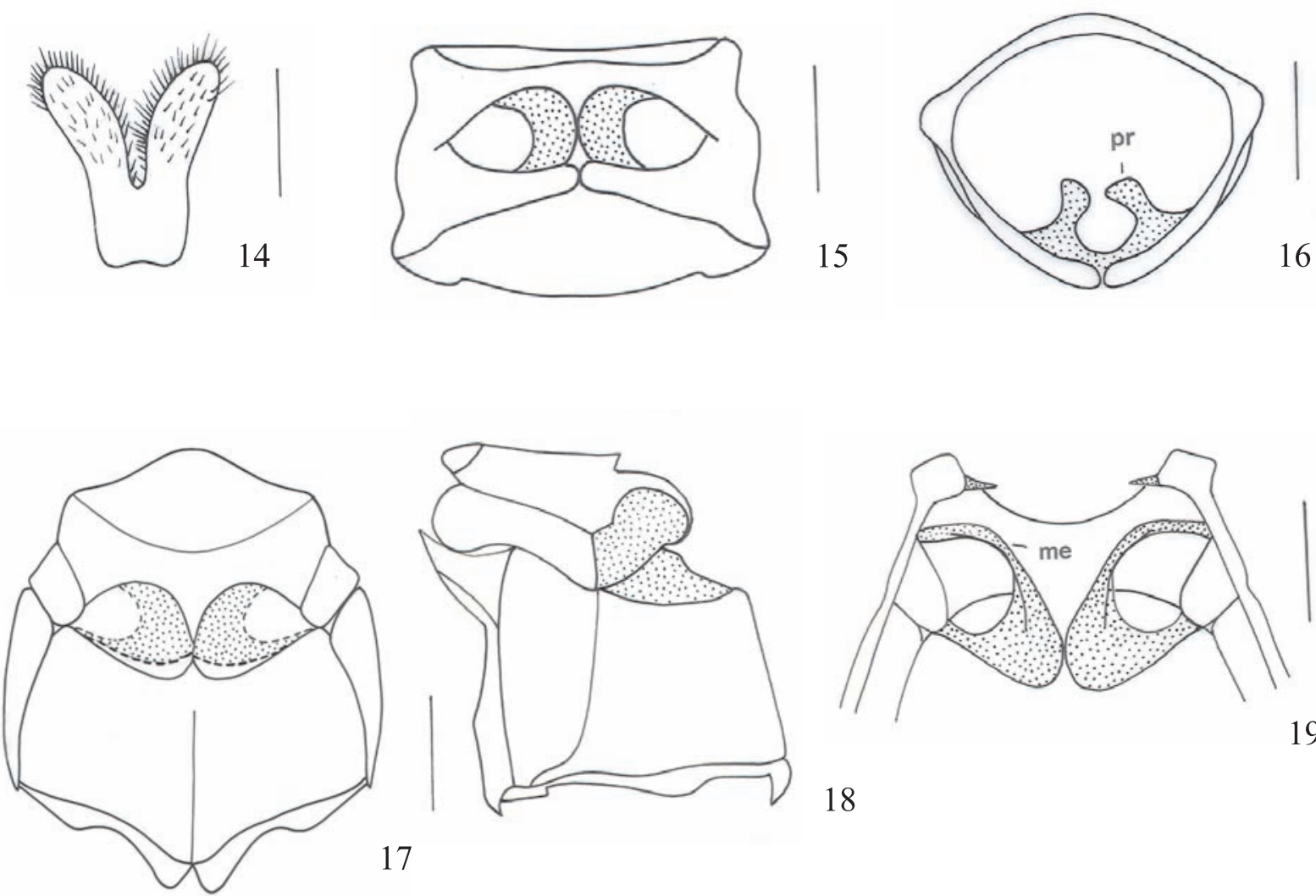

17

18
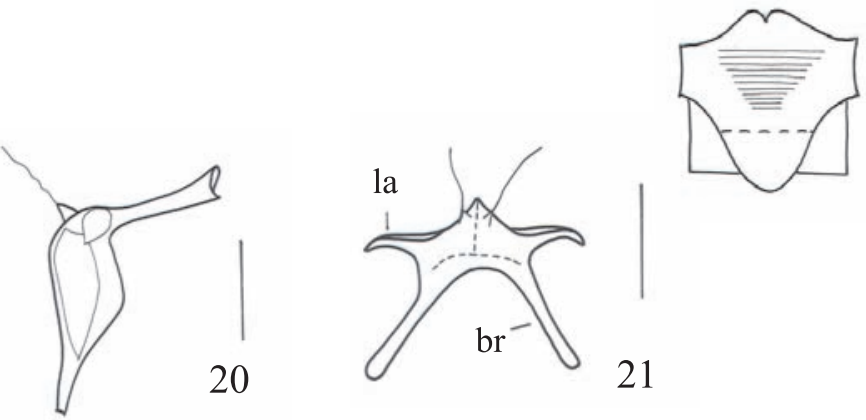

22
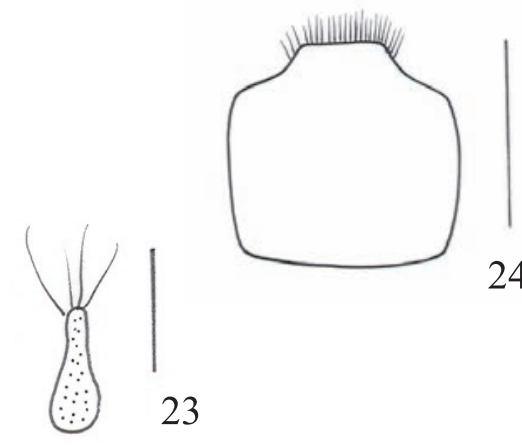

21

Figs. 10-24. Agathomerus (Agathomeroides) flavomaculatus (Klug, 1824). Mandíbula: 10, dorsal; 11, ventral; 12, maxila; 13, lábio; 14, lígula, dorsal; 15, prosterno; 16, proendosternito; mesosterno e metasterno: 17, ventral; 18, lateral; 19, mesendosternito; metendosternito: 20, dorsal; 21, lateral; 22, mesoscuto e escutelo; 23, empódio; 24, tergito VIII, ơ (br, braço; la, lâmina; me, mesendosternito; pr, proendosternito). Barras: 1,0 mm, Figs. 10-22, 24; 0,5 mm, Fig. 23. 


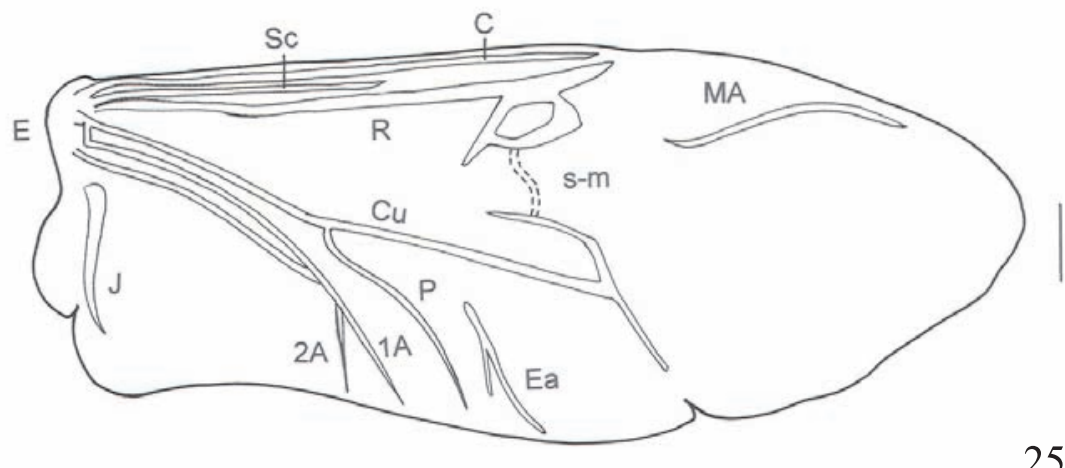

25

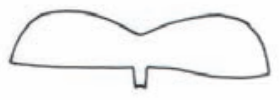

26

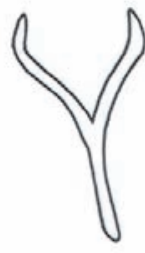

27
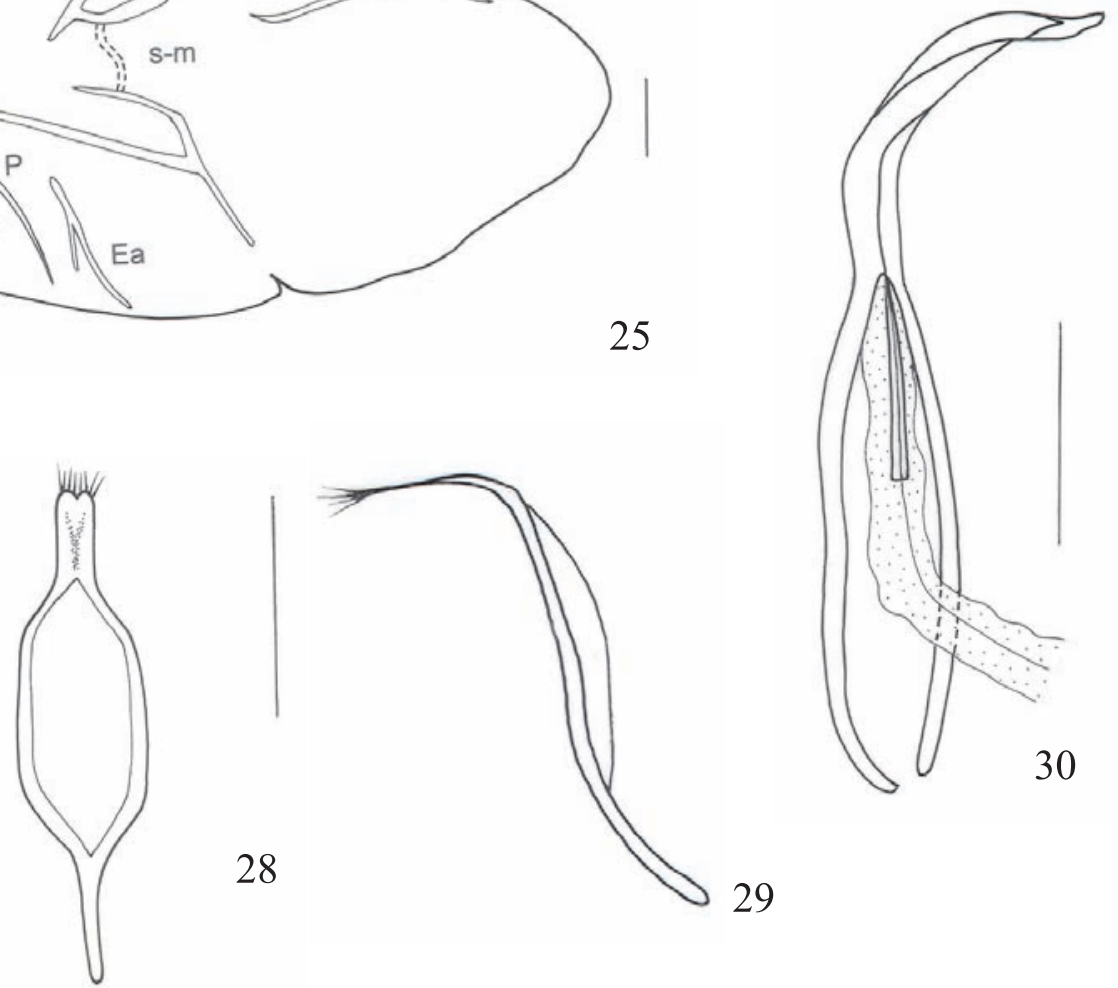

29
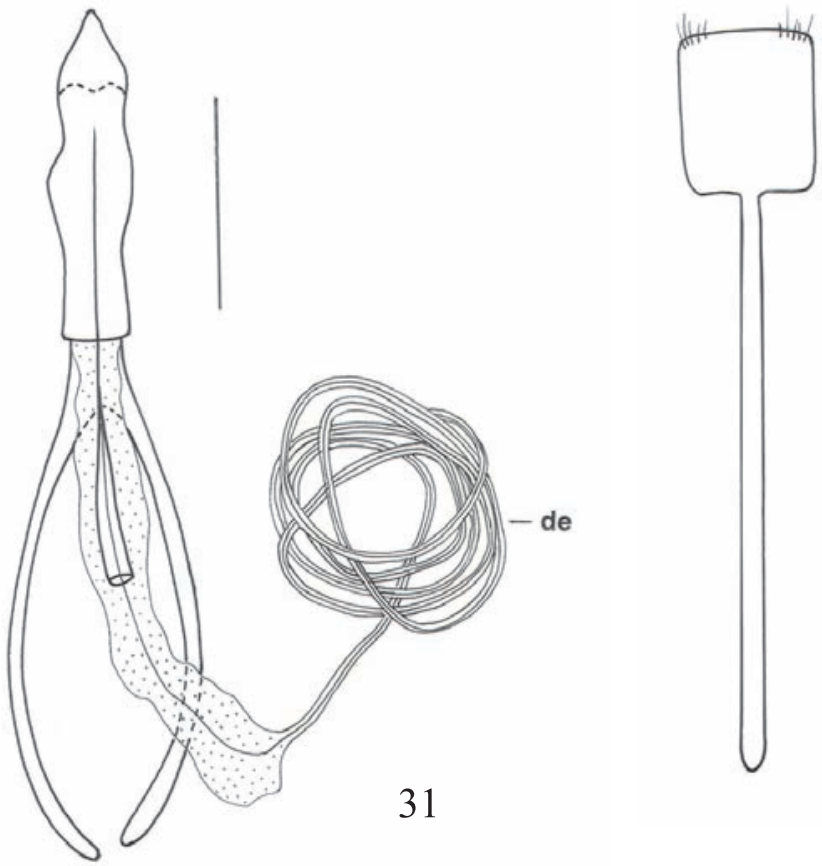

32

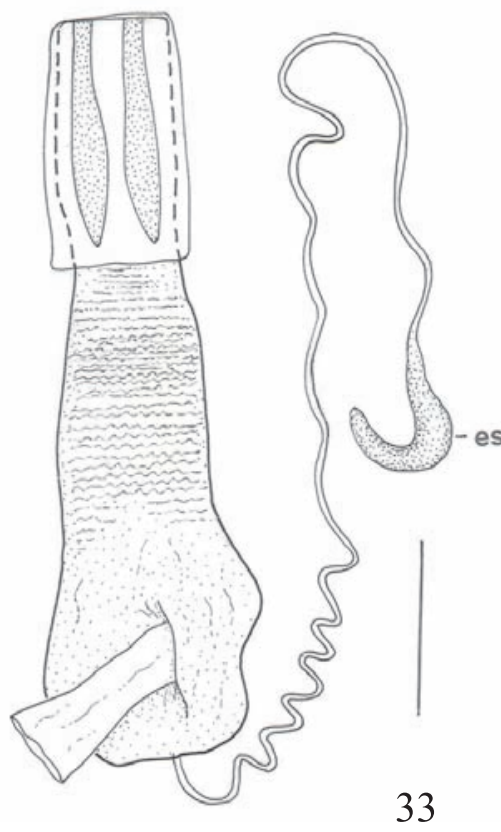

Figs. 25-33. Agathomerus (Agathomeroides) flavomaculatus (Klug, 1824). 25, asa; 26, esternito VIII, O'; 27, arco ventral; tégmen: 28, dorsal; 29, lateral; lobo médio: 30, lateral; 31, ventral; 32, esternito VIII, ; 33, genitália feminina. (C, Costa ; Cu, Cubital; de, ducto ejaculatório; E, Empusal; Ea, ramo a da Empusal; es, espermateca; J, Jugal; MA, Média Anterior; P, Plical; R, Radial; Sc, Subcosta; s-m, veia transversa setor média; $1 \mathrm{~A}, 1^{\underline{\underline{a}}}$ anal; $2 \mathrm{~A}, 2^{\mathrm{a}}$ anal). Barras: $1,0 \mathrm{~mm}$. 
Fêmea. Metafêmures fusiformes. Ventrito V escavado na margem apical. Esternito VIII (Fig. 32) membranoso, região distal ligeiramente mais longa que larga, retangular, margem apical truncada e com pêlos curtos próximos aos ângulos; apófise esternal cerca de quatro vezes mais longa que a região distal. Ovipositor (Fig. 33): região mediana com estrias transversais; região distal alongada, pigmentada em duas faixas longitudinais, sem lobos laterais, estilos ausentes. Ducto da espermateca pelo menos uma vez e meia o comprimento do ovipositor; espermateca curva, com ápice arredondado.

Dimensões em mm, respectivamente, $0^{T} /$. Comprimento total, 8,0/8,2; comprimento do protórax, 1,4/ 1,5 ; maior largura do protórax, 2,2/2,3; comprimento do élitro, 5,9/6,3; largura umeral, 3,6/3,4.

Distribuição geográfica. Brasil (Goiás, Minas Gerais, Espírito Santo, Rio de Janeiro, São Paulo ao Rio Grande do Sul), Paraguai e Argentina.

Plantas-hospedeiras. As larvas de Agathomerus (Agathomeroides) flavomaculatus foram coletadas em Capsicum baccatum L. (Solanaceae) e associadas ao adulto pelo coletor. Segundo Lima (1955), esta espécie pode ser encontrada danificando solanáceas em geral, especialmente folhas de pimenteira. PICANÇO et al. (1999) relataram que larvas foram observadas broqueando a base dos ramos de jiloeiro (Solanum gilo Raddi) sendo que, das 49 espécies de coleópteros coletados associados a esta planta, $A(A$.) flavomaculatus foi uma das mais abundantes.

Discussão. A larva de $A$. (A.) flavomaculatus difere de Palophagus bunyae Kuschel, 1990 (Kuschel \& MAY, 1990), principalmente, por esta apresentar corpo alongado, pernas 3-segmentadas e espiráculos com tubos anulares. $\operatorname{Em} A$. (A.) flavomaculatus o corpo é curvo, as pernas são 4-segmentadas e os espiráculos não apresentam tubos anulares. Entre os adultos de Agathomerus, A. (A.) flavomaculatus assemelha-se a A. (Euagathomerus) signatus Klug, 1824 pela mancha preta no pronoto em forma de "M". Difere pelos antenômeros IV-V subiguais em comprimento e pelos élitros glabros, castanhoalaranjados com manchas ântero-mediana e no terço apical amareladas. Em A. (E.) signatus, o antenômero IV é $1 / 3$ menor que o $\mathrm{V}$ e os élitros são amarelados, exceto úmeros e duas faixas oblíquas medianas, pretos e apresentam pêlos curtos, densos.

Material examinado. BRASIL, Goiás: Vianópolis, $3 \sigma^{7}$, XI.1931, R. Spitz col. (MZSP); Minas Gerais: Itajubá, ơ, X.1981, M. A. Monné col. (MNRJ); Pedra Azul, 700 m,, , XI.1972, Seabra \& Oliveira col. (DZUP); Rio Matipó, O', 1919, Fonseca col. (MZSP); Serra do Caraça, + , XI.1961, Kloss, Lenko, Martins \& Silva col. (MZSP); Espírito Santo: Santa Tereza, O, 3 \&, XI.1967, Cesar \& Elias col. (DZUP); São Paulo: Campinas, 5 larvas, 14.I.1987 (em Capsicum baccatum), A. L. Lourenção col.
(MZSP); 2 O’, Dirings col. (MZSP); Jundiaí, , XI.1940 (MZSP); Pindamonhangaba, + , X.1962, Exp. Dep. Zool. (MZSP); Santo André, Vila Bastos, +, II.1962, L. Stowbunenko col. (MZSP); São Paulo, $q$, Dirings col. (MZSP); Rio de Janeiro: Itatiaia, $2 \sigma^{7}$, XI.1961, Dirings col. (MZSP); Paraná: Quatro Barras, $850 \mathrm{~m}$, o', Laroca, Giacomel, Marinoni \& Mielke col. (DZUP); Ponta Grossa, +, XI.1942 (MZSP); Santa Catarina: Corupá, ․, II.1954 (MZSP); 2 o', ㅇ, XII.1945 (MZSP); 2 o', XI.1953 (MZSP); Joinville, Ơ, X.1944, S. Pohl col. (MZSP); São Bento do Sul, 3 O', 3 ㅇ, I.1950, Dirings col. (MZSP); Timbó, ơ, I.1952, Dirings col.; 3 \&, I.1953, Dirings col.; 17 ○ึ, XI.1963, Dirings col.; 7 \%, XI.1963, Dirings col.; 36 ơ, XI.1956, Dirings col.; 24 o',, , 1957, Dirings col.; 2 ơ, X.1964, Dirings col.; Rio Grande do Sul: Santo Augusto, O', X.1958, O. Roppa col. (MNRJ).

Agradecimentos. Aos curadores das instituições, pelo empréstimo do material estudado. Ao laboratório de microscopia eletrônica de varredura do Museu de Zoologia (MZSP). À FAPESP pela concessão da bolsa de estudos (Proc. 03/00511-3).

\section{REFERÊNCIAS BIBLIOGRÁFICAS}

Blackwelder, R. E. 1946. Checklist of the coleopterous insects of Mexico, Central America, the West Indies and South America. Part 4. Bulletin of United States National Museum 185:551-763.

Bruch, C. 1914. Catálogo sistemático de los coleópteros de la República Argentina, Parte 9. Revista del Museo de La Plata 19(2):346-400.

Clavareau, H. in JunK. 1913. Coleopterorum catalogus, pars 53, Chrysomelidae: Magascelinae, Megalopodinae, Clytrinae, Cryptocephalinae, Chlamysinae, Lamprosominae. Berlin, v.24, 278p.

Guérin, J. 1945. Novos Megalopodidae (Col.) Neotropicais. Revista de Entomologia 16(1/2):254-261.

1946. Novo megalopodideo (Col.) do Brasil. Livro de homenagem a R. F. d'Almeida 20:205-210.

1948. "Megalopodidae" neotropicais. Descrição de um novo gênero e novas espécies (Col.). Revista Brasileira de Biologia 8(1):69-72

1951. Megalopodides Américains des Collections du Musée Frey (Col. Phytophaga). Entomologische Arbeiten aus dem Museum G. Frey 2(2):576-578.

KLUG, F. 1824. Entomologische Monographien. Berlin, Reimer. 242 p.

Kuschel, G. \& May, B. M. 1990. Palophaginae, a new subfamily for leaf-beetles, feeding as adult and larva on Araucarian pollen in Australia (Coleoptera: Megalopodidae) Invertebrate Taxonomy 3:697-719.

Lacordaire, M. T. 1845. Monographie des Coleoptères Subpentamères de la famille des Phytophagues. Mémoirs de la Societé Royal des Sciences de Liège 2(5):609-721.

Lima, A. M. DA C. 1936. Terceiro catálogo systematico dos insectos que vivem nas plantas do Brasil. Rio de Janeiro, Ministério de Agricultura, Escola Nacional de Agronomia. v.4, 460p.

1955. Insetos do Brasil. $9^{\circ}$ Tomo, Coleópteros, $3^{\text {a }}$ Parte. Rio de Janeiro, Escola Nacional de Agronomia. 289p.

Monrós, F. 1947. Revisión de los Megalopodidae Argentinos (Col., Chrysomeloidea). Revista de la Sociedad Entomologica Argentina 13:150-217.

Picanço, M.; Leite, G. L. D.; Bastos, C. S.; Suinaga, F. A. \& Casali, V. W. D. 1999. Coleópteros associados ao jiloeiro (Solanum gilo Raddi). Revista Brasileira de Entomologia 43(1/ 2):131-157.

Recebido em dezembro de 2005. Aceito em julho de 2006. ISSN 0073-4721

Artigo disponível em: www.scielo.br/isz 